NASATM- $-97-207738$

\title{
Seeded physical vapor transport of cadmium-zinc telluride crystals: growth and characterization
}

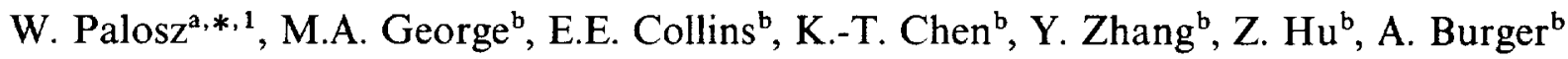

"NASA-Marshall Space Flight Center, ES75, Huntsville, Alabama 35812, USA

' Department of Physics, Fisk University, Nashville, Tennessee 37208, USA

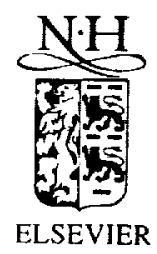




\section{Journal of Crystal Growth}

EDITORIAL BOARD

M SCHIEBER (Principal Editor)

The Fredy and Nadine Herrmann

Graduate School of Appl. Sci.

Hebrew University, Jerusalem 91904, Israel

Telefax: + 972-2-566 3878

R KERN

CRMC $^{2}$, CNRS, Campus Luminy, Case 913

F-13288 Marseille Cedex 9, France

Telefax: + 33-91-4-418916
R.S. FEIGELSON

Ctr. Materials Res, $105 \mathrm{McCu}$ lough BId

Stanford Univ. Stanford, CA 94305-4045, USA

Telefax: + 1-415-7233044

T. NISHINAGA

Dept. Electron. Eng., Univ. of Tokyo

7-3-1, Hongo, Bunkyo-ku, Tokyo 113, Japan

Telefax: +81-3-5684-3974

\section{ASSOCIATE EDITORS}

A. BARONNET (Industrial, Biological, Molecular Crystals) CRMC $^{2}$, CNRS, Campus Luminy, Case 913

F.13288 Marseille Cedex 9, France

Telefax: + 33-91-4-418916

K.W. BENZ (Microgravity, Electronic Materials)

Kristallographisches Inst., Universität

Hebelstr. 25, D-79104 Freiburg, Germany

Telefax: + 49-761-203 4369

A.A. CHERNOV (Kinetics of Crystallization Protein Crystallization)

Inst. Crystallography, Acad of Sciences

Leninskii Prosp Moscow 117333, Russian Fed.

Telefax: + 7-095-135011

A.Y. CHO (Molecular Beam Epitaxy)

Room IC-323, AT\&T Bell Laboratories

Murray Hill, NJ 07974-2070, USA

Telefax: + 1-908-582 2043

B. COCKAYNE (IOCG News)

School of Metallurgy and Mater.

Univ. Birmingham, P.O. Box 363,

Telefax: + 44-121-4712207

S.R. CORIELL (Theory)

A153 Mater, Natl Inst of Standards \& Technol

Gaithersburgh, MD 20899-0001, USA

Telefax: + 1-301-975-4553

M.E. GLICKSMAN (Solidification)

School of Eng., Mater. Eng. Dept.

Rensselaer Polytechnic Inst.

Troy, NY 12180-3590, USA

Telefax: + 1.518-2768554

MAG. HALLIWELL ( $X$-ray Diffraction)

Philips Analytical $X$-ray, Leiyweg I

7602 EA Almelo, The Netherlands

T. HIBIYA (Oxides, Melt Thermophysical Properties,

Microgratity)

Fundamental Res. Labs., NEC COR PORATION

34. Miyukigaoka, Tsukuba 305, Japan

Telefax: + 81-298-566136
H. KOMATSU (Proteins Molecular Crystallization, Growich from Solutions)

Inst. Mater. Res., Tohoku Univ.

Katahira 2-1-1, Sendai 980, Japan

Telefax: + $81-22-2152011$

T.F. KUECH (Thin Films and Electronic

and Optical Devicesl

Dept. Chem. Eng., Univ. Wisconsin-Madison

Madison, WI 53706, USA

Telctax + 1-608-265 3782

A. MCPHERSON (Protein Growth)

Telefax: + 1-909-787 3790

P.A. MORRIS HOTSENPILLER (Electrooptical Crystals, Book Reviews, Oxide Thin Films

E.I. du Pont de Nemours \& Co., Exp. Station

Wilmington, DE 19888-0358, USA

Teletax: + 1.302.6951664

J. MULLIN (Semiconductors)

EMC, "The Hoo", Brockhill Road

West Malvem, Worcs., WR 14 4DL, UK

Telefax: + 44-1684-575 591

K. NAKAJIMA (Liquid and Vapor Phase Epilaxy) Integrated Mater. Lab., Fujitsu Labs. Ltd. Morinosato-Wakamiya 10-1, Atsugi 243-01, Japan Telefax: + 81-462-483473

H. OHNO (Epitaxy)

Research Inst. of Electrical Commun.

Tohoku Univ., Sendai 98077 , Japan

The $+81 \cdot 22-2175553$

K. PLOOG (Molecular Beam Epitaxy)

Paul-Drude-Inst. für Festkörperelekıroni Hausvogteiplatz 5-7, D.10117 Berlin, Germany Telefax: + 49-30-203 7720

F. ROSENBERGER (Protein Crystallization,

Fluid Dynamics)

Center for Microgravity and Materials Research

Univ Alabama, Huntsville, AL 35899, USA

Telefax: + 1-205-8906791
Dept. Biochemistry, Univ. of California

Riverside, CA 92521, USA
D.T.J. HURLE

H.H. Wills Phys. Lab., Univ. Bristol

Tyndall Avenue

Bristol BS8 ITL, UK

G.B. STRINGFELLOW

Dept Mater $5 \mathrm{ci} 304$ EMRO, Univ. of Utah

Salt Lake City, UT 84112, USA

Telefax: +1-801-5814816
R.W ROUSSEAU (Solution Growth,

Industrial Crystalfization)

School of Chem Eng. Georgia Inst. of Technol.

Atlanta, GA 30332-0100, USA

Telefax: + 1-404-894 2866

K. SATO (Biocrystallization and

Organic (rystals)

Fac. Appl. Biol. Sci., Hiroshima Univ

Higashi-Hiroshima 724, Japa

Telefax: + 81-824-22706

L.F. SCHNEEMEYER (Superconductitity

Oxides, Novel Materials)

Room IA-363, AT\&T Bell Labs.

Murray Hill, NJ 07974-2070, USA

Telefax: + 1-908-582 2521

D.W. SHAW (Semiconductors, Epitaxy, Devices) Texas Instruments Inc., P.O. Box 655936, MS 147 Dallas, TX 75265, USA

Telefax + 1-214-995778

1. SUNAGAWA (Minerals)

3.54-2 Kashiwa-cho, Tachikawa-shi

Tokyo 190, Japan

Telefax: + 81.-425-353637

G. VAN TENDELOO (Electron Microscopy

Fullerenes, Superconductivity)

University of Antwerp, RUCA

Groenenborgerlaan 17i, B-2020 Antwerp-Belgium

Telefax: + 32-3-2180217

A.F. WITT (Semiconductor Crystals)

Dept. of Metall. \& Mater. Sci, Massachusetts

Inst of Technol Cambridze, MA 02139, USA

Telefax + 1-617-2535827

A. ZANGWILL (Theory (Epitaxy)

School of Physics, Georgia Inst. of Technol.

Atlanta, GA 30332, USA

Telefax: + 1-404-8949958

\section{Scope of the Journal}

Experimental and theoretical contributions are invited in the following fields: Theory of Experimental and theor mocular kinetics and transport phenomena, crystallization in nucleation and grewth, molecular viscous media such as polymers and glasses. Crystal gical substances in bulk or as semiconductors, magnetics, inorganic, organic and biological substances in bulk or as thin fims. Apparatus instrumentation and techniques for crystal growth, and purifica-

Abstracted/Indexed in:

Aluminium Industry Abstracts; Chemical Abstracts; Current Contents; Physical, Alumich Engineering Index; INSPEC; Metals Abstracts
Subscription Information 1997

Volumes 170-181 of Journal of Crystal Growth (ISSN 0022-0248) are scheduled for publication (Frequency: semimonthly.) Prices are available from the publishers upon pequest. Subscriptions are accepted on a prepaid basis only. Issues are sent by SAL (Sura upon request. Please address all enquiries regarding orders and subscriptions to:

Elsevier Science, B.V., Order Fulfilment Department

P.O. Box 211, 1000 AE Amsterdam, The Netherlands

Tel: +31204853642 . Fax +31204853598

Claims for issues not received should be made within six months of our publication (mailing) date. US mailing potice Journal of Crystal Growh (ISSN 0022-0248) is published semimonthly by Elsevier Science B.V, Molenwer 1, P.O. Box 211 , 1000 AE Amsterdam, The Netherlands. A

NY 11431.

US postmasters: Send address changes to Journal of Crystal Growth, Publications Expediting, Inc., 200 Meacham Avenue, Elmont NY I1003. Airfreight and mailing in the USA by Publications Expediting.

(2) The paper used in this publication meets the requirements of ANSI/NISO Z39.48-1992 (Permanerce of Paper)

PRINTED IN THE NETHERLANDS 


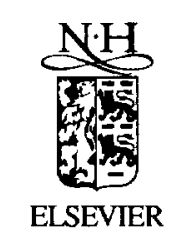

Journal of Crystal Growth 174 (1997) 733-739

\title{
Seeded physical vapor transport of cadmium-zinc telluride crystals: growth and characterization
}

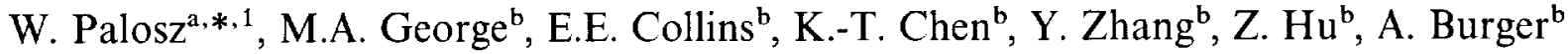 \\ "NASA-Marshall Space Flight Center, ES75, Huntsville, Alabama 35812, USA \\ 'Department of Physics, Fisk University, Nashville, Tennessee 37208, USA
}

\begin{abstract}
Crystals of $\mathrm{Cd}_{1-x} \mathrm{Zn}_{x} \mathrm{Te}$ with $x=0.2$ and $40 \mathrm{~g}$ in weight were grown on monocrystalline cadmium-zinc telluride seeds by closed-ampoule physical vapor transport with or without excess $(\mathrm{Cd}+\mathrm{Zn})$ in the vapor phase. Two post-growth cool-down rates were used. The crystals were characterized using low temperature photoluminescence, atomic force microscopy, chemical etching, X-ray diffraction and electrical measurements. No formation of a second, $\mathrm{ZnTe}$-rich phase was observed.
\end{abstract}

PACS: $81.05 . \mathrm{Dz} ; 61.72 . \mathrm{Qq} ; 78.60 . \mathrm{Ya}$

Keywords: Physics vapor transport; Cadmium-zinc telluride

\section{Introduction}

Cadmium-zinc telluride is a ternary material with applications in IR and $\gamma$-detectors. $\mathrm{Cd}_{1-x} \mathrm{Zn}_{x} \mathrm{Te}$ substrates allow for improved perfection and performance of IR detectors relative to CdTe-based devices [1]. Addition of $\mathrm{ZnTe}$ improves the energy resolution of CdTe-based $\gamma$-detectors [2]. Cadmium-zinc telluride crystals are

\footnotetext{
* Corresponding author. Fax: + 1205544 8762; e-mail: witold.palosz@msfc.nasa.gov.

${ }^{1}$ Universities Space Research Association.
}

usually grown from the melt [3-5]. Improved growth conditions (lower growth temperature, good stoichiometry, reduced impurity level) and related improvement in the crystal quality may be achieved by physical vapor transport (PVT) techniques. Recently we conducted theoretical and experimental studies on the transport of $(\mathrm{Cd}, \mathrm{Zn}) \mathrm{Te}$ and "contactless" crystal growth by PVT [6 8]. In this paper we present our results on $(\mathrm{Cd}, \mathrm{Zn}) \mathrm{Te}$ bulk crystals grown by seeded PVT. The crystals were characterized by chemical etching, photoluminescence, atomic force microscopy, $\mathrm{X}$-ray diffraction, and electrical measurements. 


\section{Crystal growth}

Crystal growth experiments werc performed in fused silica ampoules of inner diameter $1524 \mathrm{~mm}$. The starting material was pre-synthesized and pretreated as described in Ref. [7]. The source material was compacted and loaded into the growth ampoule with a seed crystal and excess $\mathrm{Cd}$ (when desired). After evacuation and back-filling with hydrogen, the ampoule was sealed. Other ampoule and growth parameters are shown in Table 1. During growth the furnace was translated relative to the (stationary) ampoule at a rate approximating that of the crystal growth. After growth the ampoule was cooled down either by turning the power off or by a slow cooling program (procedures $A$ and $B$, respectively). In the first case (A) the temperature of the crystal dropped from about 1000 to $200^{\circ} \mathrm{C}$ in $6.5 \mathrm{~h}$. During the programmed procedure $(\mathrm{B})$, cooling down to $800^{\circ} \mathrm{C}$ occurred at a rate of $10 \mathrm{C} / \mathrm{h}$, and was followed by a subsequent cooling at

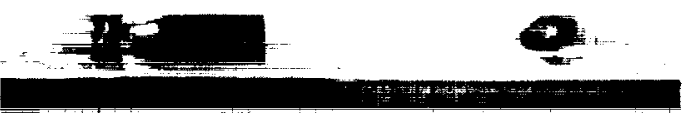

(a)

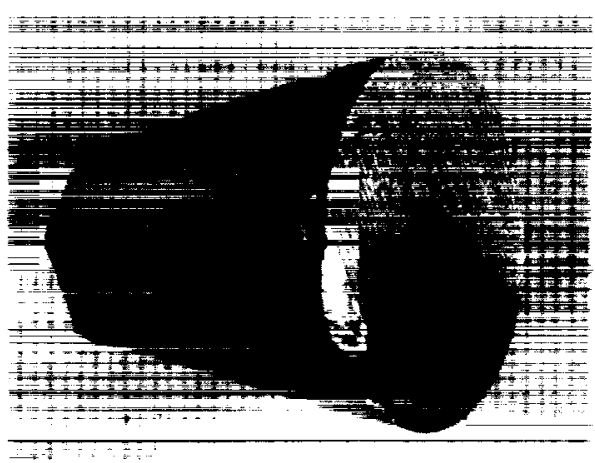

(c)
Table 1

Experimental parameters

\begin{tabular}{ll}
\hline Source material & $\begin{array}{l}\text { Pre-synthesized and sintered } \\
\text { (Cd, Zn)Te powder [7] }\end{array}$ \\
\hline Initial composition & $0.04 ; 0.2 \mathrm{~L}$ \\
Amount of source & $20-50 \mathrm{~g}$ \\
Excess component & $0.05 \mathrm{~atm} \mathrm{H}$ or $0.10 .2 \mathrm{~atm}$ \\
& $\mathrm{Cd}\left(\mathrm{at} T_{\text {source }}\right)$ \\
$T_{\text {source }}$ & $1000 \mathrm{C}$ \\
Temperature gradient at the & $2040 \mathrm{C} / \mathrm{cm}$ \\
crystal vapor interface & \\
Average crystal growth rate & $14 \mathrm{~mm} / \mathrm{day}$
\end{tabular}

$20^{\circ} \mathrm{C} / \mathrm{h}$. A typical ampoule, crystals after growth, and representative radial composition profiles of the crystals (obtained with a microprobe) are shown in Fig. 1a-Fig. 1d, respectively. Large monocrystalline grains can be obtained (Fig. Ic). The radial compositions are reasonably uniform across most of the boule (Fig. Id). However, in agreement with our previous measurements,

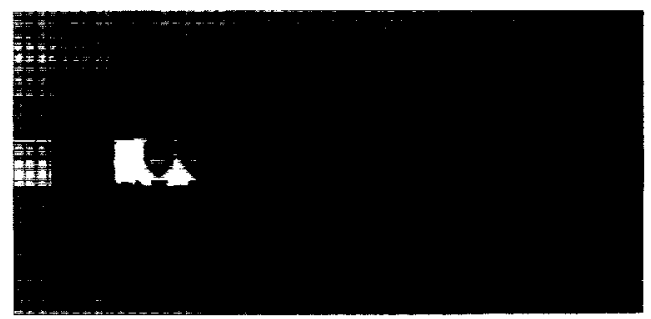

(b)

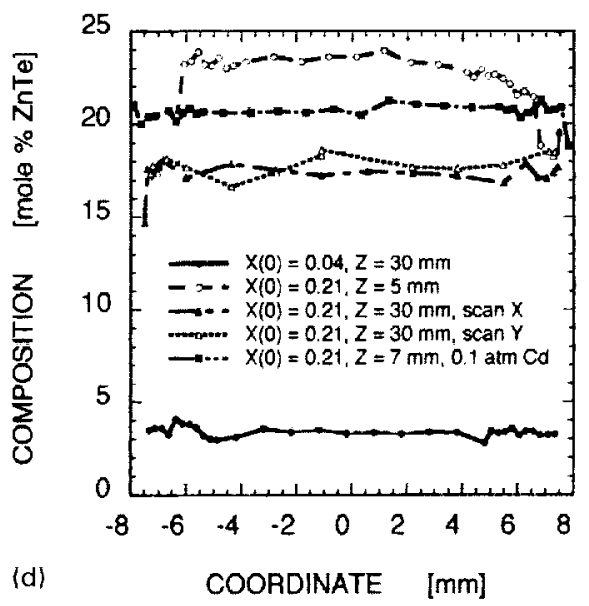

Fig. 1. (a) Ampoule after growth; (b), (c) crystals; (d) radial composition profiles. $Z$ is the distance from the seed crystal. 
crystals grown without excess $\mathrm{Cd}$ showed axial composional nonuniformities [6-8].

\section{Characterization}

\subsection{Etching}

Selected samples of the grown crystals were chemo-mechanically polished with $2 \% \mathrm{Br}$ in ethy- lene glycol and etched using Inoue [9] and/or Nakagawa [10] etch. It was found that etch pits in zinc-cadmium telluride are more difficult to obtain than in pure CdTe, particularly for higher $\mathrm{ZnTe}$ content samples. The crystals have EPD values usually about $10^{5} \mathrm{~cm}^{-2}$ or less (Fig. 2), in some cases up to about $5 \times 10^{5} \mathrm{~cm}^{-2}$. Subgrains were observed in crystals of low ZnTe content cooled slowly (procedure B) after growth (Fig. 2b). No
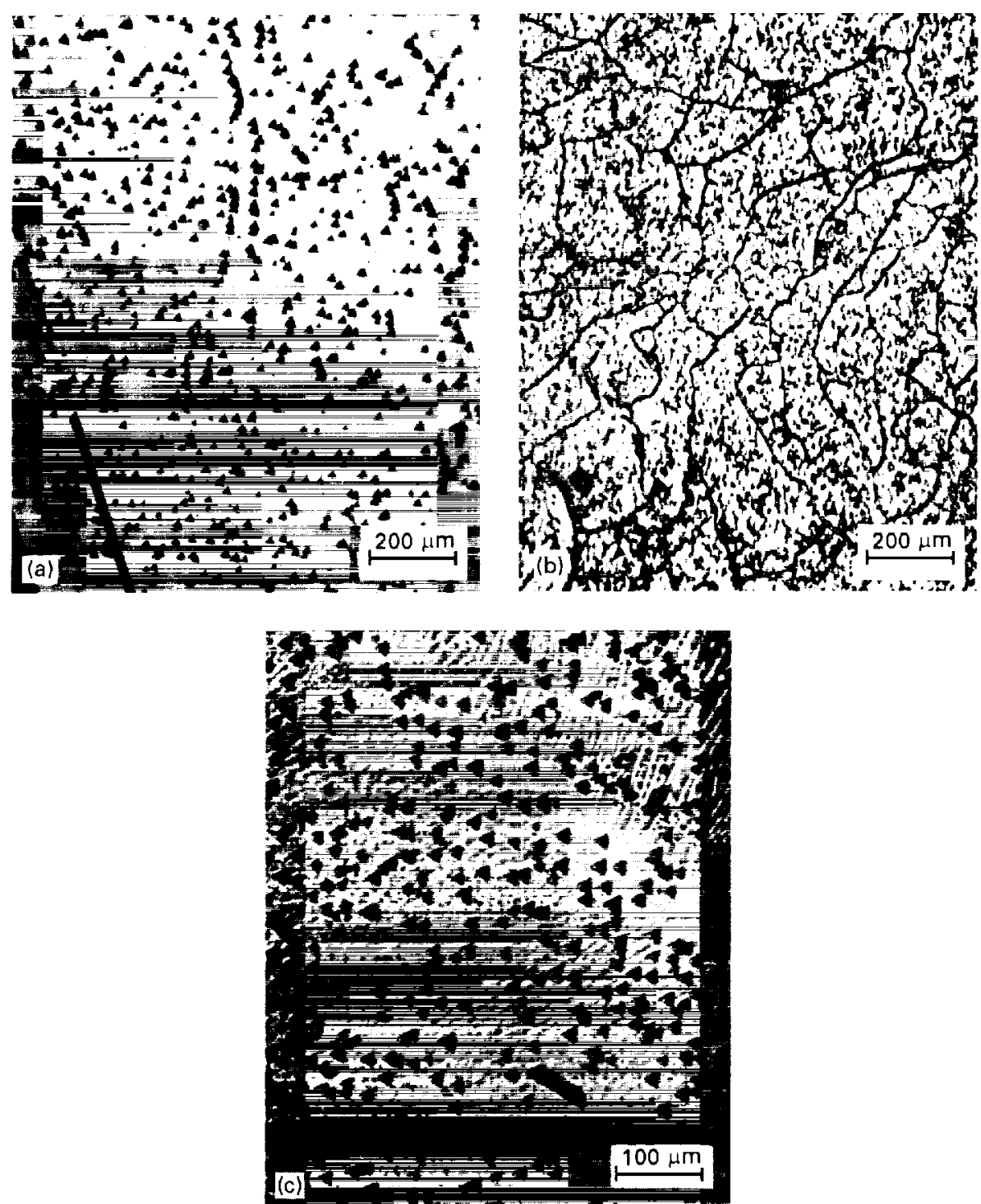

Fig. 2. Etch pits. (a) $x=0.04$, excess $(C d+Z n)$, cool-down $A$; (b) $x=0.04$, no excess $(C d+Z n)$, cool-down $B$; (c) $x=0.14$, no excess $(\mathrm{Cd}+\mathrm{Zn})$, cool-down A. 
specific dependence of the etch pit density and pattern on crystal composition and excess $(\mathrm{Cd}+\mathrm{Zn})$ in the vapor was found.

\subsection{Photoluminescence (PL)}

Low temperature PL measurements were performed on crystal samples which were cooled down to $10.6 \mathrm{~K}$ by APD Cryogenic Inc. system equipped with dual HC-4 MK 1 helium compressors. The $514.5 \mathrm{~nm}$ line, with a power density of $15 \mathrm{~mW} / \mathrm{mm}^{2}$ from an ILT $5500 \mathrm{~A}$ air-cooled argon ion laser was selected for excitation. The PL spectra were recorded using a Spex 1877D Triplemate Spectrophotometer and a liquid nitrogen cooled CCD detector. In the spectrograph stage of the spectrometer, a $30 \mu \mathrm{m}$ slit and a 300 grooves $/ \mathrm{mm}$ grating were employed. A spectrum typical for our $(\mathrm{Cd}$, $\mathrm{Zn}) \mathrm{Te}$ samples is shown in Fig. 3a. Considering the origin of the emission lines, the PL spectra can be divided into three regions (from right to left, Fig. 3a): (i) the bound exciton recombinations (BE) $[11,12]$; (ii) donor-acceptor pair (DAP) transitions [13]; and (iii) emission associated with crystal defects (DEF) $[13,14]$. The exciton nature of the edge peak (BE) of the crystals was confirmed by a superlinear dependence of the PL amplitude of the edge peak on excitation intensity. While in binary materials these are usually sharp peaks (no kinetic energy broadening) in ternary crystals some disorder-in- duced broadening occurs. The position of the exciton peak was used to determine the composition of the $\mathrm{Cd}_{1-x} \mathrm{Zn}_{x} \mathrm{Te}$ samples using the empirical formula [13]

$$
\varepsilon(\mathrm{BE})=1.589+(0.65 \pm 0.01) x+(0.19 \pm 0.02) x^{2} .
$$

The peak at about $0.05 \mathrm{eV}$ below the bound exciton position can be attributed to the donor-acceptor pair transitions, the presence of which is primarily due to extrinsic defects in the lattice [13]. The third, broad emission region lies about $0.17 \mathrm{eV}$ below the bound exciton line. Since we used undoped and high purity materials, the peak is apparently associated with cadmium vacancy related defects $[13,14]$.

The composition of the crystals determined from the position of the bound-exciton peak is in a good agreement with independent measurements made using energy dispersive $\mathrm{X}$-ray spectroscopy and wavelength dispersive $\mathrm{X}$-ray spectroscopy techniques, and with our previous results. Good compositional uniformity of the crystals was obtained with excess $\mathrm{Cd}$ in the vapor or a reverse temperature gradient in the source region [6-8]. PL spectra of several samples from each crystal were taken. In most cases, the DAP peak was small, the peak intensity ratio $J_{\mathrm{BE}} / J_{\mathrm{DAP}}$ was over 100 . The DEF peaks were usually higher, the ratio $J_{\mathrm{BE} /} / J_{\mathrm{DFF}}$
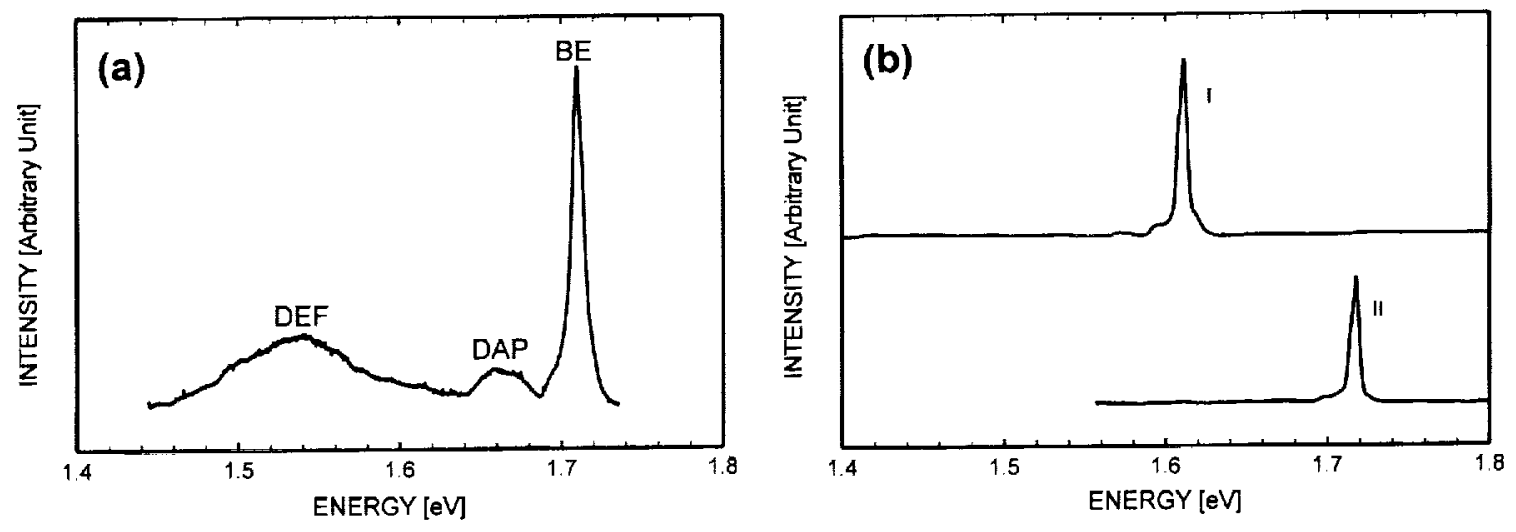

Fig. 3. Photoluminescence spectra. (a) general features: bound exciton (BE), donor-acceptor pair (DAP), and deep impurity and crystal defects (DEF) transitions; (b) I: $x=0.04$, no excess (Cd $+\mathrm{Zn}$ ), II: $x=0.19$, excess (Cd $+\mathrm{Zn})$. 

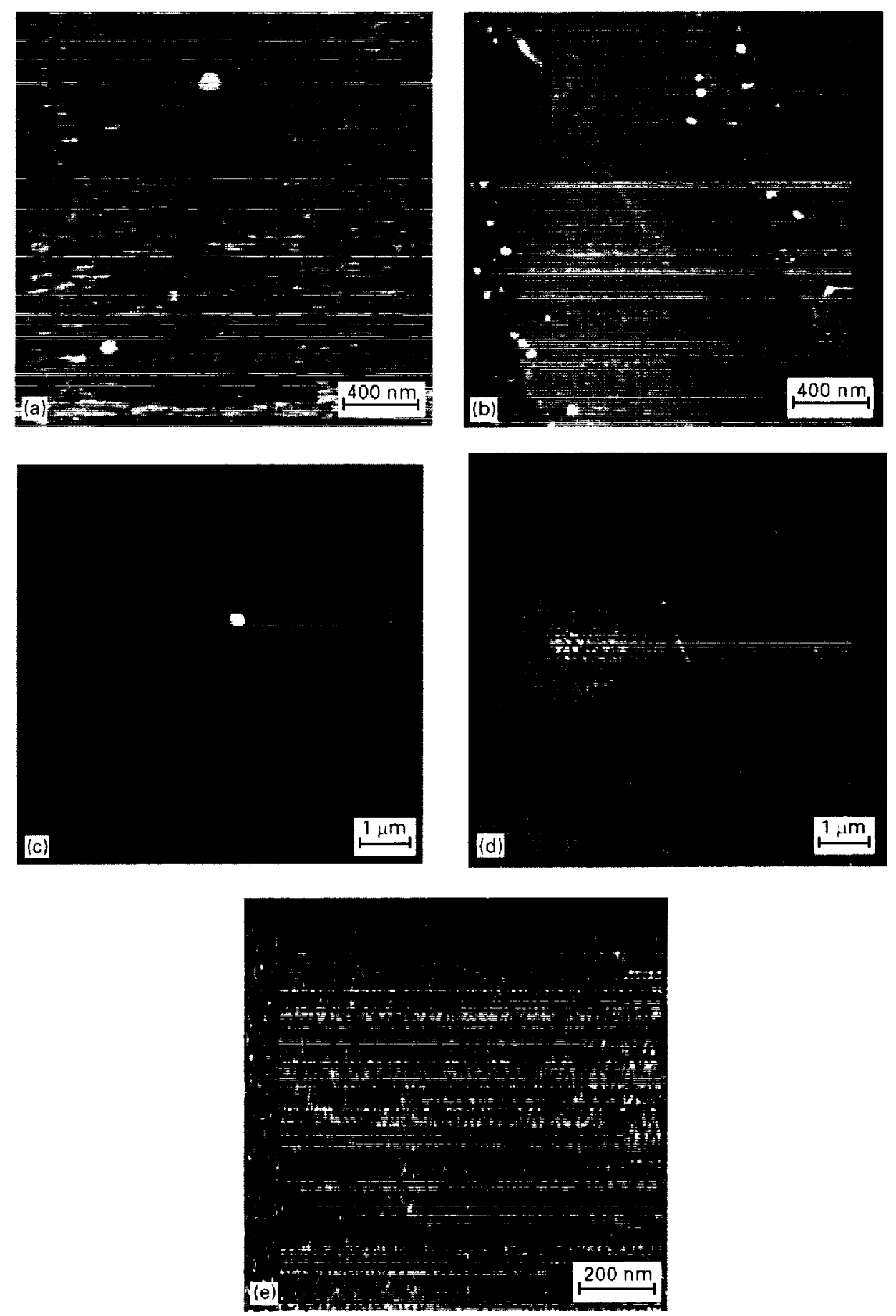

Fig. 4. Atomic force microscopy images. (a)-(d) precipitates; (e) voids. (a), (b), (c) and (e) constant height mode; (d) constant force mode. 

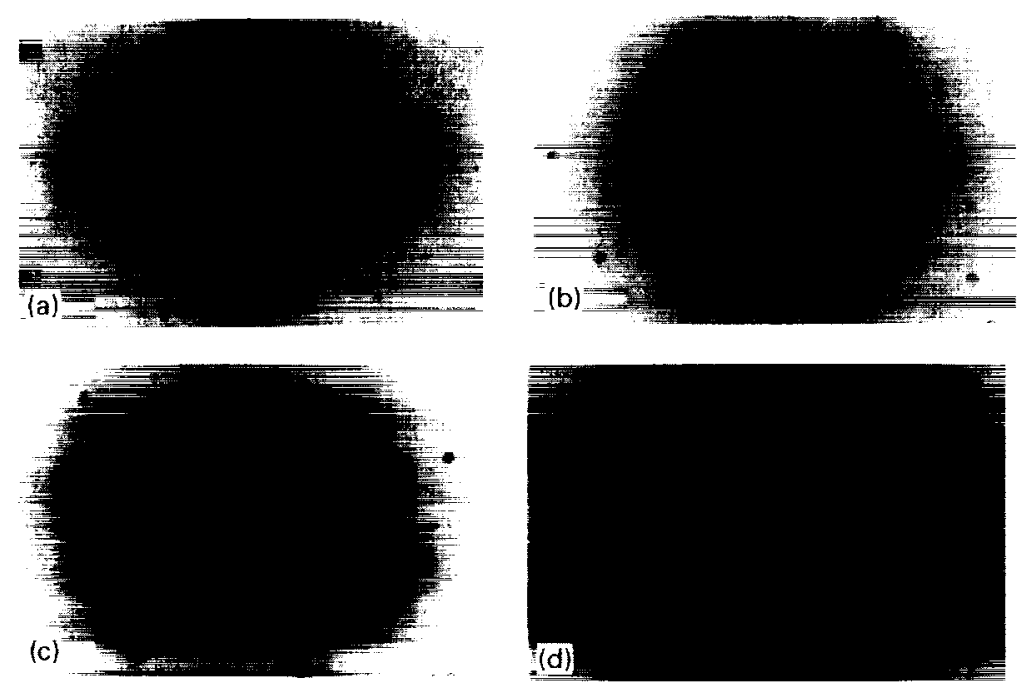

Fig. 5. Laue patterns. (a) $x=0.04$, cool-down A; (b) $x=0.04$, cool-down $\mathrm{B}$; (c) $x=0.14$, cool-down $\mathrm{A}$; (d) $x=0.20$, cool-down B.

exceeded 100 only in some samples. PL spectra of our better crystals are shown in Fig. 2b. No apparent effect of excess $(\mathrm{Cd}+\mathrm{Zn})$ pressure on $\mathrm{PL}$ spectra of the grown crystals was observed.

\subsection{Atomic force microscopy}

The morphology of freshly cleaved $\left\{\begin{array}{lll}1 & 1 & 0\end{array}\right\}$ surfaces of selected samples was investigated with the AFM technique. It was found that the cleaved surfaces are very smooth, with the (average) roughness typically in the $0.10 .3 \mathrm{~nm}$ range. This indicates good compositional microhomogeneity of the crystals. Submicron precipitates were found in some samples (Fig. 4a-Fig. 4c). The precipitates are usually small, with a size of $20-50 \mathrm{~nm}$ (Fig. 4a). An increased number of the precipitates was observed in slowly cooled (procedure B) crystals of low $(x=0.04$, Fig. 4b) but not high $(x=0.2)$ content of $\mathrm{ZnTe}$. Sometimes precipitates a few hundred nanometers in size were found (Fig. 4c). Larger size precipitates (above $100 \mathrm{~nm}$ ) were found in crystals grown under $\mathrm{Cd}$-excess pressure. Their presence is observed primarily in low ZnTe-content crystals and is accompanied by an occasional occurrence of a much larger size feature (about $1 \mu \mathrm{m}$ in diameter, Fig. 4d). Sub-micron voids were sometimes observed at locations $20-30 \mathrm{~mm}$ from the seed crystal
(Fig. 4e). They might have been caused by an insufficient interfacial temperature gradient resulting in morphological instabilities.

\subsection{Additional characterization}

$\mathrm{X}$-ray Laue diffraction patterns for low- and high-ZnTe content and for both post-growth cooldown rates are shown in Fig. 5a-Fig. 5d. The Laue patterns show good crystallinity without a second (ZnTe-rich, Refs. $[15,16])$ phase. The resistivity of most crystals is in the range $10^{3}-2 \times 10^{5} \mathrm{~cm}$ and is independent of the growth conditions.

\section{Summary}

Relatively large crystals of cadmium-zinc telluride have been grown on seeds by physical vapor transport. Both low $(x=0.04)$ and high $(x=0.2)$ $\mathrm{ZnTe}$-content crystals were obtained. Subgrain boundaries were found to form only in low $\mathrm{ZnTe}$ concentration crystals when slow post-growth cool-down is applied. PL spectra and AFM measurements show that high quality crystals can be obtained by this method. No apparent second phase (ZnTe-rich phase) has been detected even after a slow post-growth cool-down of the crystals. 
A small excess of $(\mathrm{Cd}+\mathrm{Zn})$ in the vapor phase $(0.1-0.2 \mathrm{~atm})$ improves compositional homogeneity without any meaningful effect on the crystal morphology.

\section{Acknowledgements}

The authors are pleased to acknowledge the support of this work by the National Research Council Associateship Programs (W.P.), and by the Microgravity Science and Applications Division of the National Aeronautics and Space Administration through the Marshall Space Flight Center and NASA/Fisk Center for Photonic Materials and Devices.

\section{References}

[1] A. Szilagyi and M.-N. Grimbergen, J. Crystal Growth 86 (1988) 912.

[2] J.F. Buttler, C.L. Lingren and F.P. Doty, IEEE Trans. Nucl. Sci. 39 (1992) 605.

[3] R. Triboulet, G. Neu and B. Fotouhi, J. Crystal Growth 65 (1983) 262.
[4] M. Bruder, H.-J. Schwartz, R. Schmitt, H. Maier and M.-O. Möller, J. Crystal Growth 101 (1990) 266.

[5] P. Cheuvart, U. El-Hanani, D. Schneider and R. Triboulet, J. Crystal Growth 101 (1990) 270.

[6] W. Palosz, S.L. Lehoczky and F.R. Szofran, J. Crystal Growth 148 (1995) 49

[7] W. Palosz, F.R. Szofran and S.L. Lehoczky, J. Crystal Growth 148 (1995) 56.

[8] W. Palosz, K. Grasza, D. Gillies and G. Jerman, J. Crystal Growth 169 (1996) 20

[9] M. Inoue, I. Teramoto and S. Takayanagi, J. Appl. Phys. 33 (1962) 2578

[10] K. Nakagawa, K. Maeda and S. Takeuchi, Appl. Phys. Lett. 34 (1979) 574.

[11] M.G. Peters, A.L. Fahrenbruch and R.H. Bube, J. Vac. Sci Technol. A 6 (1988) 3098.

[12] J. Garcia-Garcia, J. Gonzales-Hernandez, E. Lopez-Cruz, G. Conteras and J.G. Mendoza-Alvarez, J. Appl. Phys. 67 (1990) 3810.

[13] J. Gonzales-Hernandez, E. Lopez-Cruz, D.D. Allred and W.P. Allred, J. Vac. Sci. Technol. A 8 (4) (1990) 3255.

[14] C.B. Davis, D.D. Allred, A. Rayes-Mena, J. GonzalesHernandez, O. Gonzales, B.C. Hess and W.P. Allred, Phys. Rev. B 47 (20) (1993) 13363.

[15] M.-O. Ruault, O. Kaitasov, R. Triboulet, J. Crestou and M. Gasgnier, J. Crystal Growth 143 (1994) 40.

[16] A. Marbeuf, R. Druilhe, R. Triboulet and G. Patriarche, J. Crystal Growth 117 (1992) 10. 



\title{
Journal of Crystal Growth
}

\author{
Instructions to Authors (short version)
}

Submission of papers

Manuscripts (one original + two copies), should be sent to a member of the Editorial Board or preferably to an appropriate subject Associate Editor. News or announcements should be submitted through the Principal Editor; a duplicate should be sent directly to Elsevier Science B.V., address given below.

Original material. Submission of a manuscript implies it is not being simultaneously considered for publication elsewhere and that the authors have obtained the necessary authority for publication.

\section{Types of contributions}

Original research papers, Letters to the Editors and Priority communications are welcome. They should contain an Abstract (of up to 200 words) and a Conclusion section, which particularly in the case of theoretical papers translates the results into terms readily accessible to most readers.

As a guideline: experimental papers should not be longer than 16 double-spaced typed pages, and 8 figures + tables; for theoretical papers a maximum of 20 pages and 10 figures + tables is suggested.

Letters and Priority communications should not be longer than 5 double-spaced typed pages, and 3 figures + tables. They will be given priority in both the refereeing and production processes. The faster production schedule may preclude sending proofs of Letters and Priority communications to authors.

\section{Manuscript preparation}

Contributions may be written in English, French or German. They should have an abstract in English. The paper copies of the text should be prepared with double line spacing and wide margins, on numbered sheets.

Structure. Please adhere to the following order of presentation: Article title, Author(s), Affiliation(s), Abstract, PACS codes and keywords, Main text, Acknowledgements, Appendices, References, Figure captions, Tables.

Corresponding author. The name, complete postal address, telephone and fax numbers and the e-mail address of the corresponding author should be given on the first page of the manuscript.

Classification codes/keywords. Please supply one to four classification codes (PACS and/or MSC) and up to six keywords of your own choice that describe the content of your article in more detail.

References. References to other work should be consecutively numbered in the text using square brackets and listed by number in the Reference list. Please refer to the more detailed instructions for examples.

\section{Illustrations}

Illustrations should also be submitted in triplicate: one master set and two sets of copies. The line drawings in the master set should be original laser printer or plotter output or drawn in black india ink, with careful lettering, large enough $(3-5 \mathrm{~mm})$ to remain legible after reduction for printing. The photographs should be originals, with somewhat more contrast than is required in the printed version. They should be unmounted unless part of a composite figure. Any scale markers should be inserted on the photograph itself, not drawn below it.
Colour plates. Figures may be published in colour, if this is judged essential by the Editor. The Publisher and the author will each bear part of the extra costs involved. Further information is available from the Publisher.

\section{After acceptance}

Important. When page proofs of the accepted manuscripts are made and sent out to authors, this is in order to check that no undetected errors have arisen in the typesetting (or file conversion) process. At the proof stage only printer's errors may be corrected. No changes in, or additions to, the edited manuscript will be accepted.

Notification. The authors will receive the final answer of acceptance or rejection from the Office of the Principal Editor and will be invited to supply an electronic version of the accepted text, if this is not already available.

Capyright transfer. In the course of the production process you will be asked to transfer the copyright of the article to the Publisher. This transfer will ensure the widest possible dissemination of information.

\section{Electronic manuscripts}

The Publisher welcomes the receipt of an electronic version of your accepted manuscript. If there is not already a copy of this (on diskette) with the journal editor at the time the manuscript is being refereed, you will be asked to send a file with the text of the accepted manuscript directly to the Publisher by e-mail or on diskette (allowed formats $3.5^{\prime \prime}$ or 5.25" MS-DOS, or 3.5" Macintosh) to the address given below. (When e-mailing a non-ASCII word-processor file, you should encode it, e.g. with UUENCODE or BinHex, so as to retain all formatting codes.) The name and version of the word-processing program and the type of operating system should always be indicated. Please note that no deviations from the version accepted by the Editor of the journal are permissible without the prior and explicit approval by the Editor. Such changes should be clearly indicated on an accompanying printout of the file.

\section{Author benefits \\ No page charges. Publishing in Journal of Crystal Growth is free. \\ Free offprints. The corresponding author will receive 50 off- prints free of charge. An offprint order form will be supplied by the Publisher for ordering any additional paid offprints. \\ Discount. Contributors to Elsevier Science journals are entitled} to a $30 \%$ discount on all Elsevier Science books.

Further information (after acceptance)

Elsevier Science B.V., J. Crystal Growth

Issue Management Physics

and Materials Science

P.O. Box 2759,1000 CT Amsterdam

The Netherlands

Fax: + $31204852319 /+31204852704$

E-mail: matsci-de-f@elsevier.nl 
